\title{
GAMBARAN TEKNIK RELAKSASI NAFAS PADA IBU BERSALIN DI PRAKTIK MANDIRI BIDAN “N" TAHUN 2021
}

\section{DESCRIPTION OF BREATH RELAXATION TECHNIQUES IN MATERNITY MOTHERS IN THE PRACTICE OF MANDIRI BIDAN "N" YEAR 2021}

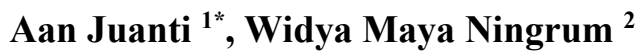 \\ ${ }^{1,2}$ Program Studi D-III Kebidanan, Fakultas Ilmu Kesehatan, Universitas Galuh \\ Jalan R.E Martadinata No.10 Ciamis 46213, Indonesia \\ *E-mail corresponding: aanjuantii@gmail.com)
}

(Diterima 17-06-2020; disetujui 24-06-2020; dipublish 27-06-2020)

\begin{abstract}
ABSTRAK
Nyeri dalam persalinan dapat memiliki dampak yang berbahaya pada ibu dan janin yaitu hiperventilasi. Tujuan penelitian ini untuk mengetahui Gambaran Teknik Relaksasi Nafas Pada Ibu Bersalin di Praktik Mandiri Bidan "N" Periode April Tahun 2021. Metode penelitian ini menggunakan metode penelitian deskriptif dengan jumlah sempel sebanyak 35 orang. Pengambilan sampel yang digunakan dalam penelitian ini adalah metode total Sampling. Diketahui Lebih dari setengahnya responden melakukan teknik relaksasi nafas pada proses persalinannya secara baik sebanyak 19 orang $(54,3 \%)$ dan kurang dari setengahnya responden melakukan teknik relaksasi nafas secara sedang pada proses persalinannya sebanyak 11 orang $(31,4 \%)$ dan sebagian kecil responden melakukan teknik relaksasi nafas pada proses persalinannya secara kurang sebanyak 5 orang $(14,3 \%)$. Lebih dari setengahnya responden melakukan teknik relaksasi nafas pada proses persalinannya secara baik.Saran: Diharapkan Tenaga kesehatan khusunya bidan sebagai penolong persalinan dapat membantu ibu bersalin dalam memenuhi kebutuhan ibu akan rasa nyaman dalam pengontrolan nyeri dan dapat meningkatkan kegiatan penyuluhan tentang teknik relaksasi nafas pada proses persalinan yang dapat membantu ibu bersalin mengurangi nyeri pada saat persalinan.
\end{abstract}

Kata kunci: Teknik Relaksasi Nafas Pada Ibu Bersalin

\begin{abstract}
Pain in labor can have a harmful impact on the mother and fetus, namely hyperventilation. The purpose of this study was to determine the description of Breath Relaxation Techniques for Maternal Maternity in the Independent Practice of Midwives "N" for the April 2021 period. This research method used a descriptive research method with a total sample of 35 people. Sampling used in this study is the total sampling method. It is known that more than half of the respondents performed breathing relaxation techniques during labor well as many as 19 people (54.3\%) and less than half of the respondents performed moderate breathing relaxation techniques during labor as many as 11 people $(31.4 \%)$ and a small proportion of respondents performed the breathing relaxation technique in less than 5 people $(14,3 \%)$. More than half of the respondents practice breathing relaxation techniques during the delivery process well. Suggestion: It is hoped that health workers, especially midwives as birth attendants, can help birth mothers in meeting the mother's need for comfort in pain control and can increase counseling activities about breathing relaxation techniques during labor. which can help mothers in labor reduce pain during labor.
\end{abstract}

Keywords: Breathing Relaxation Techniques in Maternal Maternity 


\section{PENDAHULUAN}

Nyeri pada persalinan adalah suatu keadaan yang secara umum dialami hampir semua ibu bersalin. Nyeri persalinan adalah pengalaman subjektif diakibatkan oleh iskemia otot-otot rahim, penarikan dan traksi ligament rahim, traksi ovarium, tuba fallopi dan distensi bagian bawah rahim, otot-otot panggul dan perineum. Nyeri persalinan mulai terjadi ketika kala 1 fase laten dan fase aktif, saat kala I fase laten di mulai dari pembukaan $3 \mathrm{~cm}$ biasanya berlangsung selama 8 jam. Pada saat terjadi kontraksi rahim nyeri pada saat persalinan akan bertambah sangat kuat, begitupun puncak rasa nyeri terjadi pada kala I fase aktif yang dimulai dari pembukaan belum lengkap sampai pembukaan lengkap berlangsung sekitar 4-6 jam untuk primipara dan 2-4 jam untuk multipara1

Angka kejadian nyeri persalinan dalam penelitian Maslikhanah (2010) mengatakan pada saat persalinan kala I terdapat $60 \%$ primipara menggambarkan nyeri akibat kontraksi rahim yang sangat kuat, dan 30\% nyeri sedang. Pada multipara $45 \%$ nyeri hebat, $30 \%$ nyeri sedang, dan $25 \%$ nyeri ringan. Dikarenakan ketidakcukupan dalam beradaptasi terhadap nyeri pada saat persalinan dapat membahaya ibu dan janin, maka dibutuhkan penanganan untuk mengatasi nyeri pada saat persalinan yang bertujuan agar ibu dapat beradaptasi terhadap nyeri persalinan dan tidak menimbulkan masalah atau komplikasi saat proses persalinan3.

Hasil penelitian yang dilakukan oleh. Farida (2015) didapatkan hasil bahwa teknis relaksasi nafas dapat menguragi tingkatan nyeri pada ibu bersalin. Teknik relaksasi nafas dapat dibedakan menjadi 2 yaitu teknik relaksasi nafas pada saat kala I awal dan teknik relaksasi nafas pada saat kala I akhir, di dalam penelitian teknis relaksasi nafas yang dilakukan dengan mengobservasi responden dan dilihat bagaimana tingkatan nyeri paska dilakukan teknis relaksasi nafas. Langkah yang dilakukan adalah dengan melakukan teknik relaksasi nafas dengan 12 item langkah yang harus dilakukan, peneliti menjelaskan kepada ibu untuk melakukan 12 item teknik relaksasi nafas, dan setelah diberitahu, ibu mempraktekan teknik relaksasi fas salah satu contohnya adalah ibu mempraktekan menarik nafas kembali melalui hidung dan mengeluarkan melalui mulut secara perlahan-lahan, ataupun mengusahakan agar ibu tetap berkonsentrasi sambil mata terpejam. Tujuan dari penelitian ini adalah untuk mengetahui dampak dari teknik relaksasi nafas terhadap tingkat nyeri persalinan pada ibu bersalin inpartu kala I fase aktif, didapatkan hasil menyatakan bahwa teknik relaksasi nafas berfungsi untuk mengurangi rasa nyeri $(\mathrm{P}=0,000$. Karena hasilnya $<0,05$ ) selama proses persalinan berlangsung 23 .

Dampak kecemasan dalam menghadapi proses persalinan adalah faktualisasi sikap skeptis terhadap kondisi kesehatan kecemasan terjadi karena ketidak mampuan ibu beradaptasi pada kondisi kehamilan dan kondisi menghadapi proses persalinan, dampak dari kecemasan dalam menghadapi persalinan dapat membuat ibu merasakan nyeri pada saat kontraksi, 
membuat ibu tidak tenang hal ini akan membuat memburuknya kondisi keehatan ibuk pada saat menjelang persalinan, penerapan teknik nafas pada ibu bersalin akan membantu ibu dalam mengurangi kecemasan dan dapat membantu menguranyi rasa nyeri yang dirasakan ibu

\section{METODE PENELITIAN}

Jenis penelitian ini menggunakan penelitian deskriptif. Populasi dalam penelitian ini adalah ibu bersalin kala I fase aktif degan nyeri sedang sampai berat di Praktik Mandiri Bidan periode bulan Mei 2021 dengan jumlah 35 orang. Pengambilan sampel yang digunakan dalam penelitian ini adalah metode total Sampling.

\section{HASIL DAN PEMBAHASAN}

\section{Hasil Penelitian}

Tabel 1

Distribusi Frekuensi Responden Berdasarkan Teknik Relaksasi Nafas di Praktik Mandiri Bidan "N" Tahun 2021

\begin{tabular}{lll} 
Teknik Relaksasi Nafas & F & $\mathbf{\%}$ \\
\hline Baik & 19 & 54,3 \\
Sedang & 11 & 31,4 \\
Kurang & 5 & 14,3 \\
\hline Total & $\mathbf{3 5}$ & $\mathbf{1 0 0}$
\end{tabular}

Dari tabel 1 distribusi frekuensi responden berdasarkan teknik relaksasi nafas diketahui lebih dari setengahnya responden melakukan teknik relaksasi nafas pada proses persalinanya secara baik sebanyak 19 orang $(54,3 \%)$ dan kurang dari setengahnya responden yang melakukan teknik relaksasi nafas secara sedang pada proses persalinannya sebanyak 11 orang $(31,4 \%)$ dan sebagian kecil responden melakukan teknik relaksasi nafas pada proses persalinannya secara kurang sebanyak 5 orang $(14,3 \%)$.

\section{Pembahasan}

Berdasarkan hasil penelitian diatas maka dapat diketahui bahwa lebih dari setengahnya responden yang melakukan teknik relaksasi nafas pada proses persalinannya sebanyak 19 orang $(54,3 \%)$, hal ini dikaenakan pernafasan sebagai media yang membantu ibu mempertahankan control sepanjang kontraksi, dari hasil penelitian tindakan teknik relaksasi nafas dalam yang tidak dilakukan ibu adalah poin no 7 yaitu membiarkan telapak tangan dan kaki rileks, hal ini tidak dapat dilakukan karena untuk mencapai rilek ibu harus menahan nyeri, akibat rasa nyeri ini susah untuk membuat ibu merileksasi kan tagan dan kaki, pont tindakan selanjutnya adalah Pada saat konsentrasi pusatkan pada daerah nyeri pont no 9 , hal ini sulit dilakukan karena ibu merasa untuk memfokuskan ke pusat nyeri, ibu merasakan seluruh tubuhnya merasa tidak nyaman dan nyeri di beberapa titik misalnya pinggang, perut, pinggang dan juga vagina, point selanjutnya adalah Ulangi sampai $15 \mathrm{kali}$ dengan diselingi istirahat singkat setiap 5 kali yaitu pont no 11 dimana hal ini sulit dilakukan karena sulit bagi ibu untuk mengulang kebali yang dilakukan, karena ibu mengeluh sulit untuk konstan dalam melakukan tindakan teknik tersebut.

Teknik ini bertujuan untuk merespon kontraksi uterus dan mendapatkan kenyamanan selama proses persalinan. Filososfi Lamaze merupakan suatu kelahiran 
adalah suatu hal yang normal, alami, dan sehat. Tujuannya supaya ibu pada saat melahirkan menjadi lebih percaya diri, bebas mendapatkan kenyamanan dan ketentraman, dengan diberikan dukungan emosional dan fisik dari keluarga dan tenaga professional yang percaya proses persalinan berlangsung karena kemampuan ibu. Teknik ini dapat mengurangi rasa nyeri pada saat kontraksi, meminta ibu bersalin untuk menarik nafas sedalam dalamnya melalui hidung dan mengeluarkan perlahan melalui mulut.Teknik relaksasi pernafasan sederhana sangat efektif mengurangi nyeri persalinan.

\section{KESIMPULAN DAN SARAN}

Sebanyak lebih dari setengahnya responden melakukan teknik relaksasi nafas pada proses persalinannya secara baik sebanyak 19 orang $(54,3 \%)$ dan kurang dari setengahnya responden melakukan teknik relaksasi nafas secara sedang pada proses persalinannya sebanyak 11 orang $(31,4 \%)$ dan sebagian kecil responden melakukan teknik relaksasi nafas pada proses persalinannya secara kurang sebanyak 5 orang $(14,3 \%)$.

\section{DAFTAR PUSTAKA}

Farida, F. (2015). Senam Hamil Sebagai Upaya Untuk Memperlancar Proses Persalinan Di Rumah Sakit Kasih Ibu Surakarta, Jurnal INFOKES Universitas Duta Bangsa Surakarta, Vol 5, No 1 (2015)

Maryunani Anik. (2010).Nyeri. Dalam Persalinan "Teknik dan. Cara
Penanganannya". Jakarta: CV. Trans Info Media. 